\title{
Mineralization at boiling conditions in industrial-scale analogs of hydrothermal systems
}

\author{
Y.I. KLYUKIN ${ }^{1}$, M. NightingalE ${ }^{1}$, B.M. Tutolo ${ }^{1}$ \\ ${ }^{1}$ Department of Geoscience, University of Calgary, Calgary, \\ AB, Canada T2N 1N4 (*correspondence: \\ yury.klyukin@ucalgary.ca)
}

\section{Samples}

High-pressure steam heated to temperatures up to $\sim 340{ }^{\circ} \mathrm{C}$ and pressurized up to $\sim 130$ bars is used in thermal recovery of hydrocarbons from the oil sands deposits of northeastern Alberta. Heat energy delivered with the steam lowers bitumen viscosity and mobilizes otherwise immobile hydrocarbons.

Industry strives to maximize the use of recycled water coproduced with oil to reduce costs and to reduce make-up demands. Recycled waters are subjected to treatment, to lower the hardness and silica, but most of the remaining dissolved salts and dissolved organics remain in the water. This conditioned water, otherwise named boiler feed water (BFW), is then heated in Once Through Steam Generators (OTSG) to the temperature defined by the operator (ranged between 300 to $340{ }^{\circ} \mathrm{C}$ and steam saturation pressure) to produce steam for re-injection.

Similar to natural processes, in which boiling yields mineral precipitation [1], residual solutes in BFW lead to the deposition of organic matter and minerals inside OTSG tubing. This mineralization increases the tubing temperature and may lead to premature tube failure. In the present study, we characterized mineralogy and composition of scale samples obtained from OTSG operating at multiple locations.

\section{Results}

Bulk chemistry analysis showed that the composition of scale minerals differs, depending on location. However, the composition of the precipitates is dominated by the elements $\mathrm{C}, \mathrm{Si}, \mathrm{Na}, \mathrm{Fe}, \mathrm{Mg}$ and $\mathrm{Ca}$, and to a lesser frequency P. Raman spectroscopy showed an abundance of fayalite, aegirine, and hydrated silicates of $\mathrm{Ca}, \mathrm{Fe}$ and $\mathrm{Na}$, less often hydrated phosphate minerals and oxides. Both Raman and elemental SEM-EDS maps show alternating layers enriched in either silicates or phosphates/oxides minerals with widespread organic matter. Together, these results suggest that OTSG deposits can provide interesting and well-controlled constraints on the kinetics and thermodynamics of organic matter and mineral precipitation in hydrothermal systems.

[1] Yardley \& Bodnar, (2014) Geochem. Persp., 3 